\title{
Lipid-Free PN is Associated with an Increased Risk of Hyperbilirubinemia in Surgical Critically III Patients with Admission Hepatic Disorder: A Retrospective Observational Study
}

\author{
Shih-Chi Wu (D) ${ }^{1,2, *}$ \\ Te-An Chen ${ }^{3} *$ \\ Han-Tsung Cheng ${ }^{3}$ \\ Yu-Jun Chang ${ }^{4}$ \\ Yu-Chun Wang ${ }^{3}$ \\ Chia-Wei Tzeng ${ }^{3}$ \\ Chia-Hao $\mathrm{Hsu}^{3}$ \\ Chih-Hsin Muo (iD ${ }^{5}$ \\ 'School of Medicine, China Medical \\ University, Taichung, Taiwan; ${ }^{2}$ Trauma and \\ Emergency Center, China Medical \\ University Hospital, Taichung, Taiwan; \\ ${ }^{3}$ Department of Surgery, China Medical \\ University Hospital, Taichung, Taiwan; \\ ${ }^{4}$ Epidemiology and Biostatistics Center, \\ Changhua Christian Hospital, Changhua, \\ Taiwan; ${ }^{5}$ Management Office for Health \\ Data, China Medical University and \\ Hospital, Taichung, Taiwan \\ *These authors contributed equally to \\ this work
}

Background: To evaluate the effect of different PN types on surgical critically ill trauma/ acute care surgery patients with hepatic disorders at admission.

Methods: This is a retrospective study. The PN types included lipid-free, soybean oil/ medium-chain triglyceride, olive oil-based, and fish oil-containing PNs. Patients admitted with liver injury or liver surgery, elevated serum AST/ALT level, and elevated serum total bilirubin level were included. The exclusion criteria are as follows: 1) age $<18$ years, 2) severe liver disease/cirrhosis, 3) received more than one type of PN and 4) serum total bilirubin $>4.9 \mathrm{mg} / \mathrm{dl}$ at admission. Demographics, severity, comorbidities, blood stream infection, hyperbilirubinemia (total bilirubin $>6.0 \mathrm{mg} / \mathrm{dl}$ ), and mortality were collected for analysis. We also performed analysis stratified by separated lipid doses (g/kg/day).

Results: A total of 156 patients were enrolled. There were no demographic differences among groups. The lipid-free group was associated with the highest mortality rate and incidence of hyperbilirubinemia. Compared to the lipid-free group, the olive oil-based group had the lowest risk of hyperbilirubinemia. After being stratified by separated lipid doses, the incidence of hyperbilirubinemia decreased when the lipid dosage increased. Regarding different types of lipids, patients who received more than the median dosage of lipids showed a significantly lower risk of hyperbilirubinemia, except in the fish oilcontaining group.

Conclusion: Our result suggested that lipid-free PN is associated with an increased risk of hyperbilirubinemia in surgical critically ill patients with admission hepatic disorder. Further studies are warranted.

Keywords: hyperbilirubinemia, intravenous fat emulsion, parenteral nutrition, surgical critically ill

\section{Introduction}

Parenteral nutrition $(\mathrm{PN})$ is essential in individuals with intestinal failure or those intolerant of oral or enteral nutrition for prolonged periods. ${ }^{1}$ Intravenous fat emulsions (IVFEs) are important components of PN that provide concentrated sources of cellular energy and essential fatty acids. ${ }^{2,3}$ However, it was not clear that which type of PN might be used in surgical critically ill patients with hepatic disorders at admission., ${ }^{4,5}$

The use of PN may result in parenteral nutrition associated liver disease (PNALD). The etiology of PNALD is multifactorial. ${ }^{6}$ It is characterized by
Correspondence: Shih-Chi Wu Trauma and Emergency Center, China Medical University Hospital, No. 2 Yuh-Der Road, Taichung, 404, Taiwan

Tel +886-4-22052I 21 ext. 5043

Fax +886-4-22334706

Email rwl 14@mail.cmuh.org.tw 
hepatobiliary disorders such as steatosis, cholestasis, and hepatic inflammation that can progress to cirrhosis and end-stage liver disease. ${ }^{6}$ Increased incidences of PNALD have been found in vulnerable groups, such as those with small bowel compromise, severe sepsis/infections, blood transfusions, and who received multiple surgical procedures. $^{7,8}$

Because lipid exposure and sepsis are the dominant risk factors for PNALD, the policy of lipid-free/restriction or cyclic PN has been suggested in vulnerable groups. ${ }^{9-11}$ Hence, a strategy of lipid-sparing or lipid reduction PN might be protective of the liver in adult surgical critically ill patients with liver disorders on admission.

Few studies have focused on the effect of PN (including IVFEs) in adult surgical critically ill patients with liver disorders on admission. Therefore, we were interested in this issue and tried to evaluate the effect of different PN types on surgical critically ill trauma/acute care surgery patients who were noted with hepatic disorders at admission.

\section{Methods}

From May 2013 to May 2017, we retrospectively reviewed the charts of patients with liver dysfunction and PN use in the surgical intensive care unit. Patients were characterized by either severe torso trauma or had undergone acute care surgery (eg, septic shock with hollow organ perforation, bowel ischemic changes, strangulation, hepatobiliary obstruction, etc.).

We included patients with liver injury or liver surgery, elevated serum AST/ALT level, and elevated serum total bilirubin level at admission. We excluded patients with age $<18$ years, severe liver disease or cirrhosis, or who received more than one type of $\mathrm{PN}$. We also excluded patients with severe liver insults with serum total bilirubin $>4.9 \mathrm{mg} / \mathrm{dl}$ at admission.

Management of patients included a collaborative intensive care team, prevention and control of infection, and organ support protocol. Laboratory data were collected periodically. Sedation of patients was with non-propofol sedatives. Patients received PN due to intestinal dysmotility, though not randomly, there was no preference for the use of lipid-free PNs or IVFEs in the current series. In addition, we followed the guidelines for prescription and discontinuation. ${ }^{4,5,12}$

At our institution, IVFE products include soybean oilbased/medium/long-chain triglycerides (soybean oil/MCT) (Lipovenoes ${ }^{\circledR}$ and Lipofundin $^{\circledR}$ ), olive oil-based $\left(\right.$ ClinOleic $\left.^{\circledR}\right)$ and mixed IVFE with fish oil $\left(\mathrm{SMOF}^{\circledR}\right)$.
However, a $100 \%$ soybean oil-based IVFE is not available. Therefore, there were four groups of patients: lipid-free PN, soybean oil/MCT IVFE, olive oil-based IVFE, and fish oil-containing IVFE.

In compliance with the Personal Information Protection Act, data abstracted from the chart contained no identifying patient information. All identifications of patients were substituted with surrogate numbers for research use. This study was approved by the Research Ethics Committee of China Medical University and Hospital (CMUH106-REC3 -128). We also confirmed that this study was conducted in accordance with the Declaration of Helsinki.

\section{Goal of Calorie Supplementation and PN Use}

The goal of calorie supplementation was $\leq 25 \mathrm{kcal} / \mathrm{kg}$ (actual BW)/day during the acute phase ( $48 \mathrm{~h}$ after ICU admission), followed by $30 \mathrm{kcal} / \mathrm{kg}$ (actual BW)/day during the post-acute phase ( $>4$ days postadmission). ${ }^{13}$ If EN could not be established within 72-96 h after admission, we considered the use of PN. ${ }^{4,5}$ In patients with identified preoperative malnutrition (eg, BMI $<18.5 \mathrm{~kg} / \mathrm{m}^{2}$ ) and who were intolerant to enteral feeding, we started PN within 24 $\mathrm{h}$ after ICU admission. Energy intake was initially hypocaloric nutrition with a target of 20-25 kcal $/ \mathrm{kg} /$ day and 1.5 $\mathrm{g} / \mathrm{kg} /$ day amino acids and then gradually increased to 30 $35 \mathrm{kcal} / \mathrm{kg} / \mathrm{day}$. PN could be discontinued when EN reached a target of $60 \%$ of the nutritional requirements.

\section{Definition of Hepatic Dysfunction}

There was a lack of a universal definition of hepatic dysfunction/failure. The current diagnostic criteria for hepatic dysfunction are mostly based on laboratory serum bilirubin data, which may be more than $2.0 \mathrm{mg} / \mathrm{dl}$ (>34 $\mu \mathrm{mol} / \mathrm{L})$ or more than $4.0 \mathrm{mg} / \mathrm{dl}(>70 \mu \mathrm{mol} / \mathrm{L}){ }^{14,15}$ We considered serum total bilirubin $>6.0 \mathrm{mg} / \mathrm{dl}$ as an indicator for hepatic dysfunction based on the sequential organ failure assessment (SOFA) score, which defines serum total bilirubin $>6.0 \mathrm{mg} / \mathrm{dl}$ as grade III hepatic failure. $^{16}$

\section{Assessment of Patient Severity}

We used the Acute Physiology and Chronic Health Evaluation II (APACHE II) score, SOFA score, and physiological and operative severity scores for the enumeration of mortality and morbidity scoring system (POSSUM) to evaluate the physiological status and surgical mortalities 
and morbidities of patients. The POSSUM score is often considered for surgical audits. ${ }^{17}$ Additionally, the Injury Severity Score (ISS) was used to assess the severity of trauma patients.

\section{Measurement}

We performed an analysis of the demographics (including age, sex, and body weight), pre-existing comorbidities (including sepsis, trauma, type II diabetes, hypertension, heart disease, chronic kidney disease, COPD, and receipt of transarterial embolization), severity score of illness at admission (including the admission APACHE II score, POSSUM score, SOFA score, and ISS), days from the start of PN, days of PN use, days of EN establishment, initial laboratory data, blood transfusion, hemodynamic instability on admission, receipt of abdominal operation, renal replacement therapy, blood stream infection (BSI), ventilator days, length of stay, and time to hyperbilirubinemia. Mortality was assessed at discharge and at 30, 60, and 90 days. We also assessed the effect of different lipids with regard to time to hyperbilirubinemia and mortality stratified by separated oil dosage ( $\mathrm{g} / \mathrm{kg} / \mathrm{day})$. Moreover, we used the median dosage for assessment because there was a lack of a standard dosage.

\section{Statistical Analysis}

The differences between demographic data and clinical characteristics were examined by Kruskal-Wallis tests for continuous variables and Chi-square tests/Fisher exact tests for categorical variables. We used Cox regression models to analyze the risk of hyperbilirubinemia or mortality among the IVFE groups, and showed hazard ratios (HRs) with 95\% confidence intervals (95\% CIs). The association of different oil dosages with hyperbilirubinemia and mortality among different oil types were assessed. The separated oil dosage was divided into two groups based on the median dosage of oils.

The survival probability of mortality or cumulative incidence of hyperbilirubinemia was plotted based on the Cox model after being adjusted for significant variables (Table 1). All data management and analyses were performed using the SAS 9.4 software package (SAS Institute, Cary, NC). The significance level was set at $\mathrm{p}<0.01$ under the two-tail test according to Bonferroni correction.

\section{Result}

During this 48-month period, 163 trauma/acute care surgery patients were included in the study. No patient was excluded for severe liver disease or cirrhosis or received more than one type of IVFE. Seven patients were excluded because of serum total bilirubin $>4.9 \mathrm{mg} / \mathrm{dl}$ at admission. Therefore, a total of 156 patients with admission hepatic disorders were enrolled. Among these 156 patients, 20 patients had liver injury/liver surgery, 90 patients had an elevated serum AST/ALT level, and 46 patients had elevated serum total bilirubin $(>1.2 \mathrm{mg} / \mathrm{dl})$.

There were $48(30.8 \%)$ patients in the soybean oil/ MCT IVFE group, $51(32.7 \%)$ patients in the olive oilbased IVFE group, $22(14.1 \%)$ patients in the fish oilcontaining IVFE group, and $35(22.4 \%)$ patients in the lipid-free group (Figure 1).

Among the groups, the range of the mean age was 56.762.6 years old (Table 1). Most patients were male. There were no significant differences in clinical characteristics among the groups, except for days of PN use. In addition, there were 8, 10, 4, and 15 patients with mortality at discharge in the soybean oil/MCT, olive oil-based, fish oil-containing, and lipid-free groups, respectively (Table 2). The survival probability was highest in the soybean oil/MCT group $(67.13 \%)$, but there were no significant differences among the three IVFE groups (Figure 2A). There were 13, 12, 8 and 20 patients with total bilirubin $>6.0 \mathrm{mg} / \mathrm{dl}$ at the end of follow-up in the soybean oil/MCT, olive oil-based, fish oil-containing, and lipid-free groups, respectively (Table 2 ). The cumulative incidence of total bilirubin $>6.0 \mathrm{mg} / \mathrm{dl}$ was highest in the lipid-free group (70.30\%) (Figure 2B).

After adjusting for days of $\mathrm{PN}$ use, the lipid-free group was associated with the highest mortality rate among the groups. Compared to the lipid-free group, the IVFE groups had a generally lower mortality risk. Although the lipidfree group had the highest mortality rate compared with the IVFE groups at discharge, 30 days, and 90 days, it did not reach a significant difference (Table 2).

In addition, the lipid-free group showed the highest incidence of total bilirubin $>6.0 \mathrm{mg} / \mathrm{dl}$ (36.70 per 1000 persondays), followed by the fish oil-containing group (11.73 per 1000 person-days), soybean oil/MCT group (11.34 per 1000 person-years), and olive oil-based group (8.04 per 1000 person-days) (Table 2). Compared to the lipid-free group, the olive oil-based group had the lowest risk of total bilirubin $>6.0 \mathrm{mg} / \mathrm{dl}(\mathrm{HR}=0.26,95 \% \mathrm{CI}=0.13-0.54)$ (Table 2).

Table 3 shows the effect of different lipids on the time to total bilirubin $>6.0 \mathrm{mg} / \mathrm{dl}$ stratified by the separated oil dosage. The incidence of total bilirubin $>6.0 \mathrm{mg} / \mathrm{dl}$ was decreased when the lipid dosage increased, except in the fish oil-containing group. After adjusting for days of PN use and admission initial serum T-bilirubin, when 
Table I Demographics and Clinical Characteristics

\begin{tabular}{|c|c|c|c|c|c|}
\hline \multirow[t]{2}{*}{ Variable } & Soybean Oil/MCT & Olive Oil Based & Fish Oil Contained & Lipid Free & \multirow[t]{2}{*}{ p-value } \\
\hline & $(\mathrm{N}=48)$ & $(\mathrm{N}=5 \mathrm{I})$ & $(\mathrm{N}=\mathbf{2 2})$ & $(\mathrm{N}=35)$ & \\
\hline Demographic & & & & & 0.74 \\
\hline Age $(y r)$, mean $(S D)$ & $62.6(18.5)$ & $61.8(20.2)$ & $60.7(16.2)$ & $56.7(19.5)$ & 0.49 \\
\hline Sex, n (\%) & & & & & 0.70 \\
\hline Female & $18(37.5)$ & $19(37.3)$ & $6(27.3)$ & $10(28.6)$ & \\
\hline Male & $30(62.5)$ & $32(62.2)$ & $16(72.7)$ & $25(71.4)$ & \\
\hline Body weight (kg), mean(SD) & $64.4(15.4)$ & $60.4(13.5)$ & $66.3(13.6)$ & $64.0(18.0)$ & 0.46 \\
\hline \multicolumn{6}{|l|}{ Clinical, mean(SD) } \\
\hline \multicolumn{6}{|l|}{ Severity score of illness } \\
\hline Admission APACHEll score & I7.8 (7.53) & $16.9(7.22)$ & $18.2(6.85)$ & $20.0(8.49)$ & 0.53 \\
\hline SOFA score & $5.02(2.8 I)$ & $4.75(3.24)$ & $5.05(2.57)$ & $6.31(3.11)$ & 0.10 \\
\hline Total POSSUM score & $47.5(10.4)$ & $47.3(10.7)$ & $48.4(9.57)$ & $52.4(10.1)$ & 0.15 \\
\hline ISS† & $28.0(13.3)$ & $27.4(11.6)$ & $23.9(12.0)$ & $28.8(4.38)$ & 0.81 \\
\hline Days of PN start, mean(SD) & $2.31(1.79)$ & $2.90(3.00)$ & $4.68(5.61)$ & $3.03(2.4 \mathrm{I})$ & 0.20 \\
\hline Days of EN establish, mean(SD) & $3.19(1.89)$ & $4.15(3.84)$ & $4.74(3.38)$ & $4.16(3.39)$ & 0.16 \\
\hline Days of PN use, mean(SD) & $10.8(9.70)$ & $12.2(10.4)$ & $20.5(20.2)$ & $8.86(7.42)$ & 0.01 \\
\hline \multicolumn{6}{|l|}{ Admission Biochemical variables, mean(SD) } \\
\hline Admission Initial serum T-bilirubin & $1.20(0.66)$ & $1.25(0.83)$ & $1.63(0.66)$ & $1.70(1.06)$ & 0.06 \\
\hline BUN & $35.2(28.6)$ & $32.6(24.7)$ & $34.9(37.0)$ & $26.3(18.7)$ & 0.41 \\
\hline Creatinine & $2.05(1.75)$ & $1.80(1.42)$ & $2.18(2.39)$ & $2.08(1.82)$ & 0.68 \\
\hline Serum albumin & $2.73(0.7 \mathrm{I})$ & $2.90(0.65)$ & $2.70(0.75)$ & $2.77(0.66)$ & 0.75 \\
\hline Serum Lactate (mg/dl) & $50.9(40.1)$ & $42.1(32.2)$ & $47.5(40.3)$ & $65.3(56.1)$ & 0.26 \\
\hline Serum ALT & II $2.3(209.5)$ & $83.5(132.5)$ & $97.3(202.5)$ & $118.0(132.1)$ & 0.45 \\
\hline Blood transfusion & $7.73(9.48)$ & $7.80(9.33)$ & $13.1(23.9)$ & $12.3(15.3)$ & 0.33 \\
\hline \multicolumn{6}{|l|}{ Comorbidity, n (\%) } \\
\hline Sepsis & $14(29.2)$ & $13(25.5)$ & $5(22.7)$ & $7(20.0)$ & 0.80 \\
\hline Trauma & $15(31.3)$ & $13(25.5)$ & $8(36.4)$ & $13(37.1)$ & 0.66 \\
\hline Type II diabetes & $24(50.0)$ & $19(37.3)$ & $14(63.6)$ & $18(51.4)$ & 0.19 \\
\hline Hypertension & $18(37.5)$ & $23(45.1)$ & $9(40.9)$ & $13(37.1)$ & 0.85 \\
\hline Heart disease & $2(4.17)$ & $9(17.7)$ & $4(18.2)$ & $3(8.57)$ & 0.11 \\
\hline Chronic kidney disease & $6(12.5)$ & $8(15.7)$ & $3(13.6)$ & $7(20.0)$ & 0.83 \\
\hline COPD & I (2.08) & $2(3.92)$ & $0(0.00)$ & I (2.86) & 1.00 \\
\hline Malignancy & $6(12.5)$ & $3(5.88)$ & $5(22.7)$ & $2(5.71)$ & 0.13 \\
\hline Post TAE & $5(10.4)$ & $7(13.7)$ & $2(9.09)$ & $6(17.1)$ & 0.80 \\
\hline Hemodynamic unstable on admission, $n$ (\%) & $20(41.7)$ & $19(37.3)$ & $8(36.4)$ & $14(40.0)$ & 0.96 \\
\hline Received abdominal operation, $\mathrm{n}(\%)$ & 44 (91.7) & $44(86.3)$ & $21(95.5)$ & $31(88.6)$ & 0.70 \\
\hline Vasopressor use at ER, n (\%) & $14(29.2)$ & $10(19.6)$ & $3(13.6)$ & $13(37.1)$ & 0.16 \\
\hline Received CVVH, n (\%) & $4(8.33)$ & $9(17.7)$ & $3(13.6)$ & $10(28.6)$ & 0.11 \\
\hline Received HD, n (\%) & $4(8.33)$ & $6(11.8)$ & $3(13.6)$ & $9(25.2)$ & 0.18 \\
\hline Blood stream infection, n (\%) & $22(45.8)$ & $22(43.1)$ & $6(27.3)$ & $18(51.4)$ & 0.34 \\
\hline Length of stay (day), mean (SD) & $33.3(25.1)$ & $35.2(26.5)$ & $45.8(31.0)$ & $31.9(23.1)$ & 0.22 \\
\hline Duration of ventilator days, mean(SD) & $14.5(14.4)$ & $19.9(21.7)$ & $25.2(19.6)$ & $20.9(17.1)$ & 0.06 \\
\hline Reason of liver insult, n (\%) & & & & & 0.74 \\
\hline Direct liver trauma & $5(10.4)$ & $6(11.8)$ & $2(9.09)$ & $7(20.0)$ & \\
\hline Elevated AST/ALT at admission & $29(61.4)$ & $32(62.8)$ & $13(59.1)$ & $16(45.7)$ & \\
\hline Elevated T-bilirubin level & $14(29.2)$ & $13(25.5)$ & $7(31.8)$ & $12(34.3)$ & \\
\hline
\end{tabular}

Notes: P-values were calculated by Kruskal-Wallis tests for continuous variables and Chi-square tests/Fisher exact tests for categorical variables. $\dagger$ ISS score only for trauma patients. Abbreviations: MCT, medium-chain triglyceride; TAE, transarterial embolization; CVVH, continuous veno-venous hemofiltration; HD, hemodialysis. 
Surgical critically ill patients with admission hepatic disorder and PN use $(N=163)$

Exclusion

- age $<18$ years $(\mathrm{N}=0)$

- severe liver diseases or cirrhosis $(\mathrm{N}=0)$

- received more than one type of $\mathrm{PN}(\mathrm{N}=0)$

- hyperbilinubinemia (>5.0 mg/dl) at admission $(\mathrm{N}=7)$

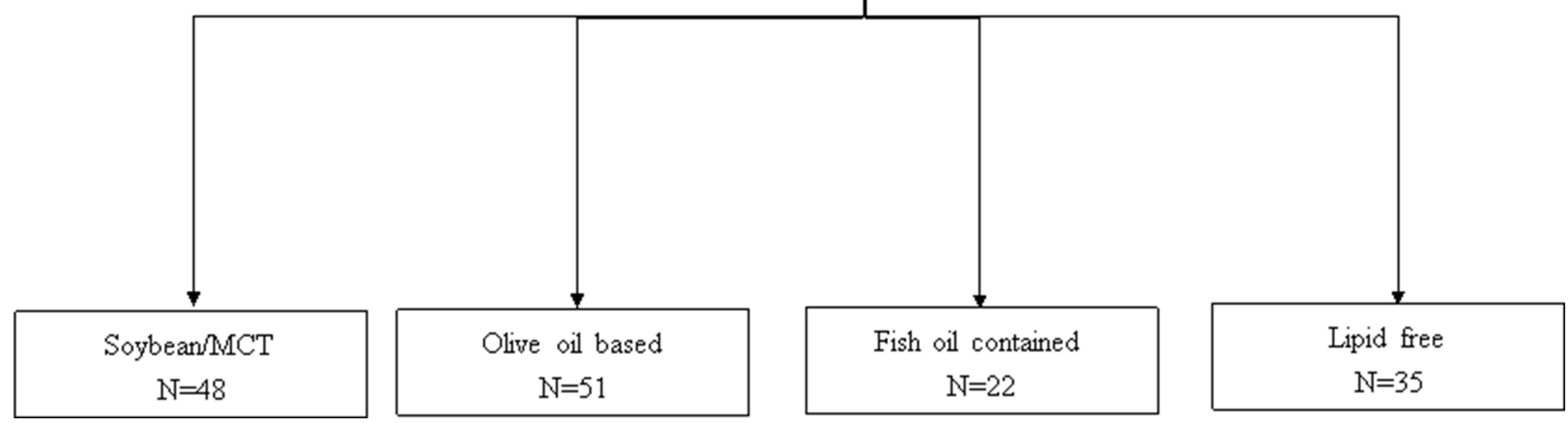

Figure I Flow chart for selecting study cohorts.

compared to nonsoybean use, the risk decreased from 0.53 $(95 \% \mathrm{CI}=0.29-0.96)$ to $0.11(95 \% \mathrm{CI}=0.04-0.27)$ in patients with soybean use greater than $0.15 \mathrm{~g} / \mathrm{kg} /$ day. Regarding the different types of lipids, patients who received more than the median dosage of lipids showed a significantly lower risk of hyperbilirubinemia, except in the fish oil-containing group.

Table 4 shows the effect of different lipids on time to in-hospital mortality stratified by separated oil dosage. After adjusting for days of PN use and admission initial serum T-bilirubin, patients receiving more than $0.15 \mathrm{~g} / \mathrm{kg} /$ day soybean oil had a significantly lower mortality risk (HR $=0.29,95 \% \mathrm{CI}=0.1-0.68)$. There were no significant dosage differences in the soybean oil/MCT, olive oilbased, and fish oil-containing groups. In addition, soybean oil showed a decreasing trend of mortality with increasing oil dosage.

\section{Discussion}

There were different characteristics among the critically ill patient subgroups. ${ }^{18}$ Surgical critically ill patients, such as trauma/acute care surgery patients, are often susceptible to shock, acute stress, hemorrhage, and multiorgan failure. ${ }^{19,20}$ Therefore, it is likely that previous therapeutic concepts and modalities might be associated with different outcomes.
Few studies have addressed the supplementation of PN types in adult patients with pre-existing liver disorders. Lipid-free/restriction or cyclic PN has been applied in children and pediatric patients. ${ }^{9-11}$ Therefore, the strategy of lipid-sparing or lipid reduction PN might be rational in adult surgical critically ill patients with liver disorders upon admission owing to the concern of further liver damage.

The ESPEN guidelines for liver disease recommend that PN should be used as a second-line treatment in patients who cannot be adequately orally fed and/or EN in patients with acute liver failure. Yet, there are limited instructions for the selection of PN types such as lipid-free PNs or IVFEs. ${ }^{4,51,22}$ Because IVFEs might be associated with steatosis, cholestasis, and hepatic inflammation, the concerns for exacerbated liver function might have impacts on the choice of $\mathrm{PN}$ in patients with hepatic disorders upon admission and might result in the preference for lipid-free PN.

Bilirubin is a potent antioxidant, and a moderate increase in plasma bilirubin has been thought to be with benefit due to antioxidant effects of this bile pigment. ${ }^{23}$ In addition, bilirubin has a new function as a ligand for peroxisome proliferator-activated receptor alpha (PPAR- $\alpha$ ), ${ }^{24,25}$ while PPAR- $\alpha$ increases UDP Glucuronosyltransferase Family 1 Member A1 (UGT1A1), ${ }^{26}$ UGT1A1 involves in the metabolism of bilirubin that lowers plasma bilirubin levels ${ }^{27}$ The fatty acids are likely activating PPAR to increase UGT1A1 as a negative 


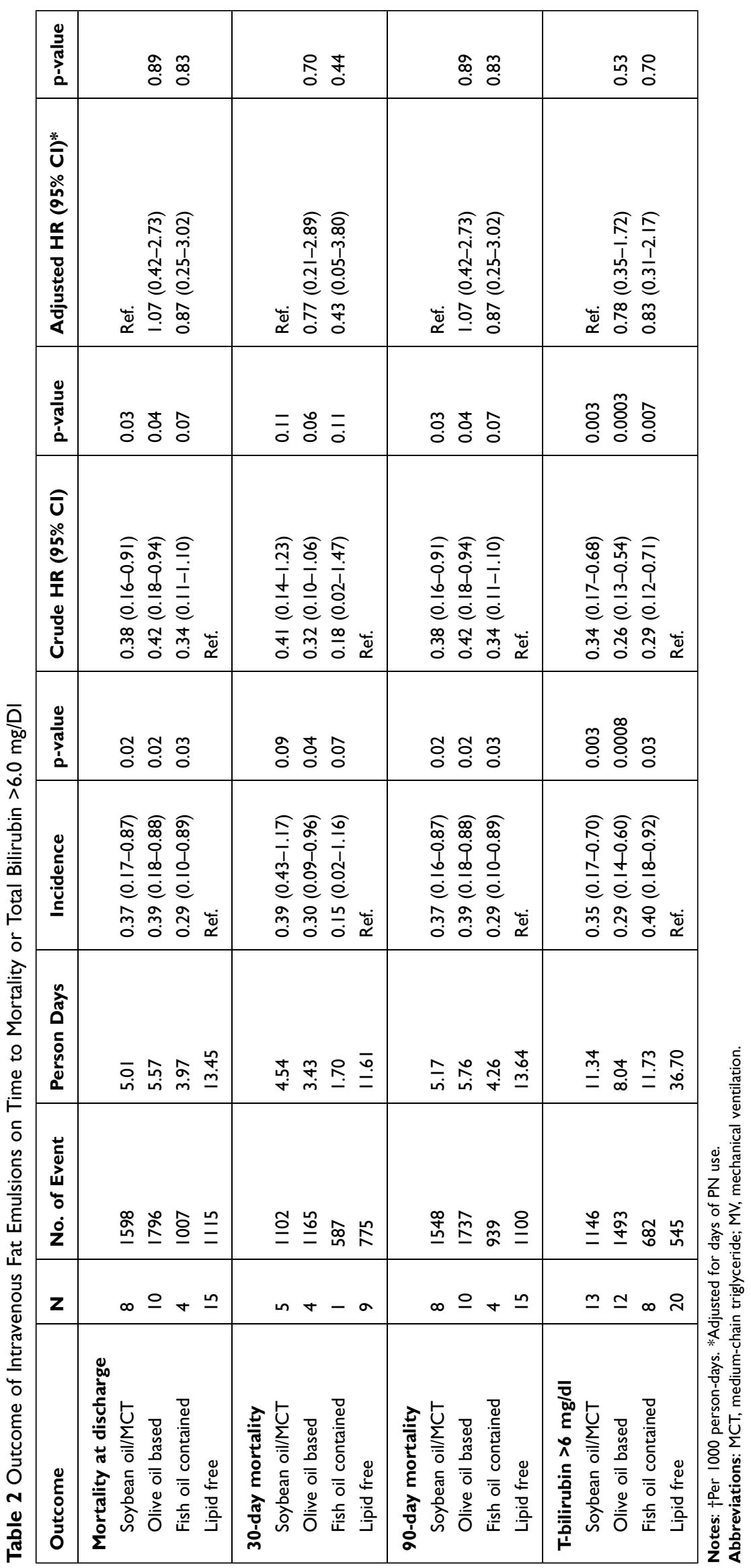


A

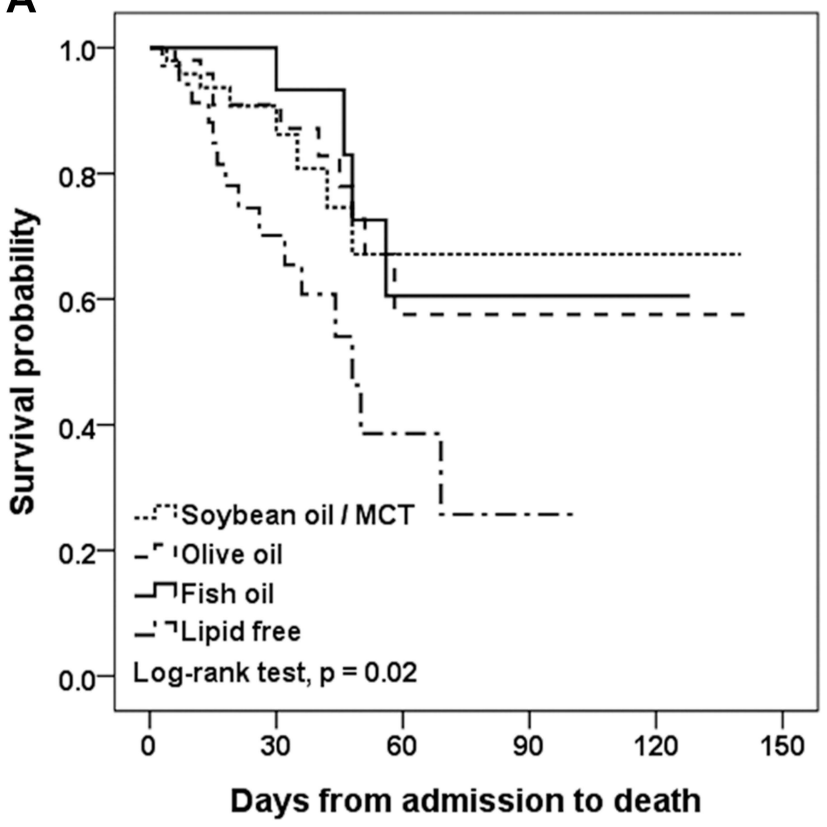

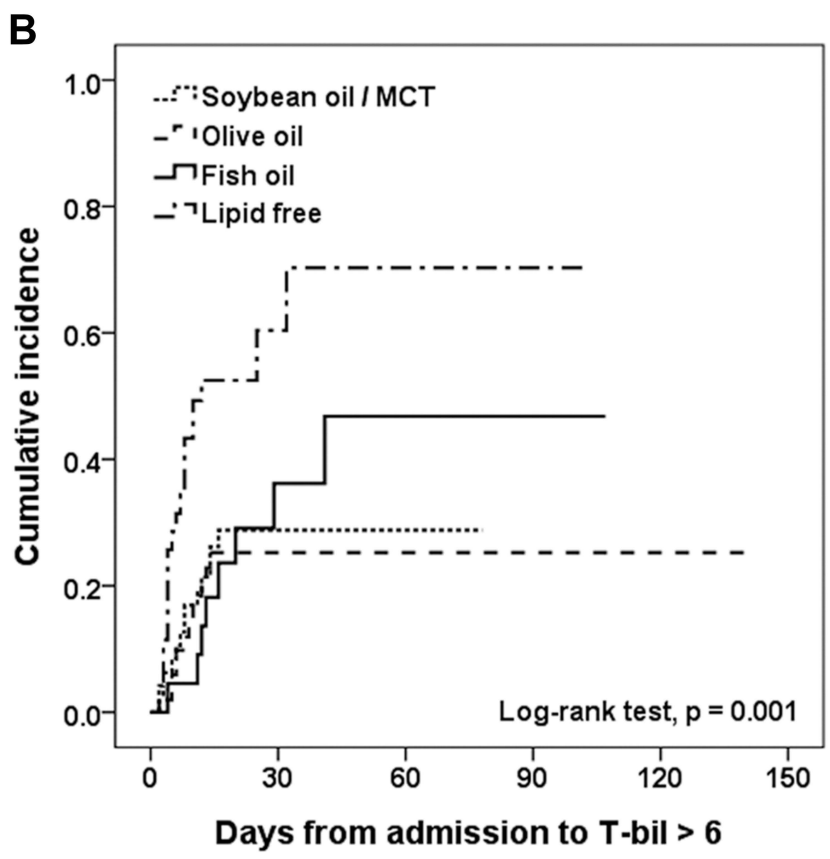

Figure 2 (A) Cumulative incidence of mortality in Kaplan-Meier analysis. The survival probability was highest in the soybean oil/MCT group (67.13\%), but there were no significant differences among the three IVFE groups. (B) Cumulative incidence of total bilirubin $>6.0 \mathrm{mg} / \mathrm{dl}$ in Kaplan-Meier analysis. The cumulative incidence of total bilirubin $>6.0 \mathrm{mg} / \mathrm{dl}$ was highest in the lipid-free group $(70.30 \%)$.

feedback loop. ${ }^{28}$ Thus, it is rational that the use of lipid-free $\mathrm{PN}$ is associated with an increased risk of hyperbilirubinemia in surgical critically ill patients with admission hepatic disorder.
In the current series, the lipid-free group was associated with the highest mortality rate among the groups, this might be attributed to the fact that lipids are essential to body biochemical activities, the structure of cell

Table 3 Effect of Different Lipids on Time to Total Bilirubin $>6.0 \mathrm{Mg} / \mathrm{DI}$ Stratified by Separated Oil Dosage (g/kg/Day)

\begin{tabular}{|c|c|c|c|c|c|c|c|c|}
\hline Variable & $\mathbf{N}$ & $\begin{array}{l}\text { No. of } \\
\text { Event }\end{array}$ & $\begin{array}{l}\text { Person } \\
\text { Days }\end{array}$ & Incidence $^{\dagger}$ & $\begin{array}{l}\text { Crude HR } \\
\text { (95\% CI) }\end{array}$ & p-value & $\begin{array}{l}\text { Adjusted HR } \\
(95 \% \mathrm{Cl})\end{array}$ & p-value \\
\hline \multicolumn{9}{|l|}{ Oil dosage } \\
\hline \multicolumn{9}{|l|}{ Soybean } \\
\hline None & 35 & 20 & 545 & 36.70 & Ref. & & Ref. & \\
\hline$\leq \operatorname{median}(0.15 \mathrm{~g} / \mathrm{kg} /$ day $)$ & 62 & 27 & |37| & 19.69 & $0.59(0.33-1.06)$ & 0.08 & $0.53(0.29-0.96)$ & 0.04 \\
\hline$>$ median & 59 & 6 & 1950 & 3.08 & $0.11(0.04-0.28)$ & $<0.0001$ & $0.11(0.04-0.27)$ & $<0.0001$ \\
\hline \multicolumn{9}{|l|}{$\mathrm{MCT}$} \\
\hline None & 69 & 28 & 1303 & 21.49 & Ref. & & Ref. & \\
\hline$\leq$ median $(0.20 \mathrm{~g} / \mathrm{kg} /$ day $)$ & 43 & 20 & 1252 & 15.97 & $0.95(0.53-1.69)$ & 0.86 & $0.78(0.4 \mid-I .48)$ & 0.45 \\
\hline$>$ median & 44 & 5 & 1311 & 3.81 & $0.21(0.08-0.55)$ & 0.001 & $0.21(0.08-0.54)$ & 0.001 \\
\hline \multicolumn{9}{|l|}{ Olive oil } \\
\hline None & 73 & 30 & 1353 & 22.17 & Ref. & & Ref. & \\
\hline$\leq$ median $(0.20 \mathrm{~g} / \mathrm{kg} /$ day $)$ & $4 I$ & 19 & 1159 & 16.39 & $0.94(0.53-1.68)$ & 0.84 & $0.75(0.39-1.42)$ & 0.37 \\
\hline$>$ median & 42 & 4 & 1354 & 2.95 & $0.18(0.06-0.50)$ & 0.001 & $0.16(0.06-0.46)$ & 0.0007 \\
\hline \multicolumn{9}{|l|}{ Fish oil } \\
\hline None & 115 & 39 & 2378 & 16.40 & Ref. & & Ref. & \\
\hline$\leq$ median $(0.05 \mathrm{~g} / \mathrm{kg} /$ day $)$ & 21 & 13 & 571 & 22.77 & $1.70(0.91-3.20)$ & 0.10 & I.28 (0.58-2.80) & 0.54 \\
\hline$>$ median & 20 & I & 917 & 1.09 & $0.10(0.01-0.75)$ & 0.03 & $0.09(0.01-0.69)$ & 0.02 \\
\hline
\end{tabular}

Notes: †Per 1000 person-days. Adjusted for days of PN use and admission initial serum T-bilirubin.

Abbreviations: MCT, medium-chain triglyceride; MV, mechanical ventilation. 
Table 4 Effect of Different Lipids on Time to in-Hospital Mortality Stratified by Separated Oil Dosage (g/kg/Day)

\begin{tabular}{|c|c|c|c|c|c|c|c|c|}
\hline Variable & $\mathbf{N}$ & No. of Event & Persondays & Incidence ${ }^{\dagger}$ & $\begin{array}{l}\text { Crude HR } \\
(95 \% \mathrm{Cl})\end{array}$ & p-value & $\begin{array}{l}\text { Adjusted HR } \\
(95 \% \mathrm{Cl})\end{array}$ & p-value \\
\hline \multicolumn{9}{|l|}{ Oil dosage } \\
\hline \multicolumn{9}{|l|}{ Soybean } \\
\hline None & 35 & 15 & 1115 & 13.45 & Ref. & & Ref. & \\
\hline$\leq \operatorname{median}(0.15 \mathrm{~g} / \mathrm{kg} /$ day $)$ & 62 & 14 & 2283 & 6.13 & $0.45(0.22-0.93)$ & 0.03 & $0.51(0.24-1.08)$ & 0.08 \\
\hline$>$ median & 59 & 8 & 2118 & 3.78 & $0.27(0.12-0.64)$ & 0.003 & $0.29(0.12-0.68)$ & 0.005 \\
\hline \multicolumn{9}{|l|}{ MCT } \\
\hline None & 69 & 21 & 1992 & 10.52 & Ref. & & Ref. & \\
\hline$\leq \operatorname{median}(0.2 \mathrm{~g} / \mathrm{kg} /$ day $)$ & 43 & 11 & 2072 & 5.31 & $0.51(0.24-1.06)$ & 0.07 & $0.62(0.28-1.40)$ & 0.25 \\
\hline$>$ median & 44 & 5 & 1452 & 3.44 & $0.3 \mid(0 . \mid I-0.8 I)$ & 0.02 & $0.31(0.12-0.83)$ & 0.02 \\
\hline \multicolumn{9}{|l|}{ Olive oil } \\
\hline None & 73 & 22 & 2245 & 9.80 & Ref. & & Ref. & \\
\hline$\leq$ median $(0.20 \mathrm{~g} / \mathrm{kg} /$ day $)$ & 41 & 7 & 1882 & 3.72 & $0.34(0.15-0.81)$ & 0.015 & $0.38(0.15-0.94)$ & 0.04 \\
\hline$>$ median & 42 & 8 & 1389 & 5.76 & $0.55(0.25-1.25)$ & 0.15 & $0.58(0.25-1.32)$ & 0.19 \\
\hline \multicolumn{9}{|l|}{ Fish oil } \\
\hline None & 115 & 28 & 3468 & 8.07 & Ref. & & Ref. & \\
\hline$\leq$ median $(0.05 \mathrm{~g} / \mathrm{kg} / \mathrm{day})$ & 21 & 7 & 1116 & 6.27 & $0.72(0.31-1.66)$ & 0.44 & $0.96(0.36-2.52)$ & 0.93 \\
\hline$>$ median & 20 & 2 & 932 & 2.15 & $0.25(0.06-1.06)$ & 0.06 & $0.28(0.07-1.21)$ & 0.09 \\
\hline
\end{tabular}

Notes: †Per 1000 person-days. Adjusted for days of PN use and admission initial serum T-bilirubin.

Abbreviations: MCT, medium-chain triglyceride; MV, mechanical ventilation.

membranes, signal transduction, and platelet function. ${ }^{29,30}$ Thus, a lack of lipids may result in fatty acid deficiency and hyperbilirubinemia, as well as possible poor outcomes.

When stratified by lipid dosage $(\mathrm{g} / \mathrm{kg} /$ day $)$, relatively higher doses were associated with a significantly lower HR of hyperbilirubinemia among each lipid, except in the fish oil-containing group. Although the use of lipids may not play an important role in the mortality of surgical critically ill patients, soybean oil showed a decreasing trend of mortality with increasing oil dosage. Together, our results might reflect, at least in part, the important role of soybean lipids for this group. However, further studies are warranted.

After adjusting for days of PN use, the lipid-free group still had a significant incidence of hyperbilirubinemia and the highest incidence of mortality among the groups. In contrast, there was no significant risk of hyperbilirubinemia and mortality among the three IVFE groups. This result may show, in part, that a lipid-free PN policy might not be sufficient in surgical critically ill patients with admission hepatic disorders and again highlighted the role of fatty acids in activating PPAR to increase UGT1A1, ${ }^{28}$ as well as the importance of essential fatty acids.

Studies showed that patients who received lipid-free PN developed hepatic steatosis possibly as a result of essential fatty acid deficiency, while hepatic steatosis resolved following lipid supplementation. ${ }^{31,32}$ However, other studies suggested the use of lipid-free/restriction or cyclic PN in pediatric patients with PNALD. ${ }^{9-11,33,34}$ These results might be attributed to physiological discrepancies between pediatric and adult patients. Although there are no solid data, we assume that the need for essential fatty acids might be increased in patients with trauma/acute care surgery. However, due to the selection of mild and moderate admission hepatic disorders, our results cannot be extrapolated to those of patients with very severe liver disorders.

It is difficult to draw meaningful conclusions from this series due to limited number of study patients. Yet, our findings suggest that there might be an association between the increased incidence of hyperbilirubinemia and the use of lipid-free PN in surgical critically ill patients with hepatic disorders at admission. In addition, a relatively higher lipid dosage seems to be associated with a lower risk of hyperbilirubinemia when stratified by separate lipid doses. However, further large-scale studies are required.

\section{Limitations of the Study}

The strengths of this study include a specific study population, reliable diagnoses, and a high follow-up rate. 
However, certain limitations exist. First, the sample size is not large. Second, the retrospective nature and lack of randomization may give rise to probable bias in case selection, which might restrict our analytical conclusions. Third, because there are multifactorial characteristics in surgical critically ill patients with severe trauma/acute care surgery, it is difficult to collect all of the related data in this study. Therefore, evaluation of physiological status and severity was performed using physiological scores rather than detailed clinical parameters. Fourth, there may be a subjective bias because the criteria for the use and types of PN are not fully quantified. Therefore, further multicenter randomized studies for this specific patient group are warranted with predefined enrollment criteria for a better understanding of this issue.

\section{Conclusion}

Our findings suggest that there might be an association between the increased incidence of hyperbilirubinemia and the use of lipid-free PN in surgical critically ill trauma/ acute care surgery patients who were noted to have hepatic disorders at admission.

However, based on the retrospective nature and limited sample size of this study, further studies are warranted.

\section{Abbreviations}

PN, parenteral nutrition; PNALD, parenteral nutrition associated liver disease; IVFE, intravenous fat emulsions.; MCT, medium-chain triglyceride; ICU, intensive care unit; BMI; body mass index; SOFA, sequential organ failure assessment; APACHE II, Acute Physiology and Chronic Health Evaluation II; POSSUM, physiological and operative severity scores for the enumeration of mortality and morbidity scoring system; ISS, Injury Severity Score; BSI, blood stream infection; AST, ASpartate aminoTransferase; ALT, ALanine aminoTransferase; HR, hazard ratios; CI, confidence intervals.

\section{Data Sharing Statement}

Please contact author for data requests.

\section{Ethics Approval and Consent to Participate}

For complying with the Personal Information Protection Act, the data abstracted from the chart contained no identification of patient information. All identifications of patients were replaced with surrogate numbers for research uses. The need for informed consent was waived by all participants. This study was approved by the Research Ethics Committee at China Medical University and Hospital (CMUH106-REC3-128).

\section{Author Contributions}

All authors contributed to data analysis, drafting or revising the article, have agreed on the journal to which the article will be submitted, gave final approval for the version to be published, and agree to be accountable for all aspects of the work. Guarantor of the article: Shih-Chi $\mathrm{Wu}, \mathrm{MD}, \mathrm{PhD}$.

\section{Funding}

This study is supported in part by Ministry of Health and Welfare, Taiwan (109-TDU-B-212-114004), MOST Clinical Trial Consortium for Stroke (MOST 108-2321B-039-003). The funders had no role in study design, data collection and analysis, decision to publish, or preparation of the manuscript.

\section{Disclosure}

The authors have declared that no competing interests exist.

\section{References}

1. Bielawska B, Allard JP. Parenteral nutrition and intestinal failure. Nutrients. 2017;9(5):466. doi:10.3390/nu9050466

2. Calder PC, Jensen GL, Koletzko BV, et al. Lipid emulsions in parenteral nutrition of intensive care patients: current thinking and future directions. Intensive Care Med. 2010;36(5):735-749.

3. Fell GL, Nandivada P, Gura KM, et al. Intravenous lipid emulsions in parenteral nutrition. Adv Nutr. 2015;6(5):600-610.

4. Weimann A, Braga M, Carli F, et al. ESPEN guideline: clinical nutrition in surgery. Clin Nutr. 2017;36(3):623-650.

5. Singer P, Blaser AR, Berger MM, et al. ESPEN guideline on clinical nutrition in the intensive care unit. Clin Nutr. 2019;38(1):48-79.

6. Tillman EM. Review and clinical update on parenteral nutrition-associated liver disease. Nutr Clin Pract. 2013;28(1):30-39.

7. $\mathrm{Xu} \mathrm{ZW}, \mathrm{Li}$ YS. Pathogenesis and treatment of parenteral nutrition-associated liver disease. Hepatobiliary Pancreat Dis Int. 2012;11(6):586-593.

8. Drongowski RA, Coran AG. An analysis of the factors contributing to the development of total parenteral nutrition-induced cholestasis. JPEN. 1989;13:586-589.

9. Nandivada P, Carlson SJ, Chang MI, Cowan E, Gura KM, Puder M. Treatment of parenteral nutrition-associated liver disease: the role of lipid emulsions. Adv Nutr. 2013;4(6):711-717.

10. Badia-Tahull MB, Llop-Talaveron J, Leiva-Badosa E. Impact of intravenous lipid emulsions on liver function tests: contribution of parenteral fish oil. Nutrition. 2015;31(9):1109-1116. doi:10.1016/j. nut.2015.04.005

11. Rollins MD, Ward RM, Jackson WD, et al. Effect of decreased parenteral soybean lipid emulsion on hepatic function in infants at risk for parenteral nutrition-associated liver disease: a pilot study. $J \quad$ Pediatr Surg. 2013;48(6):1348-1356. doi:10.1016/j. jpedsurg.2013.03.040 
12. McClave SA, Taylor BE, Martindale RG, et al. Guidelines for the Provision and Assessment of Nutrition Support Therapy in the Adult Critically Ill Patient: society of Critical Care Medicine (SCCM) and American Society for Parenteral and Enteral Nutrition (A.S.P.E.N.). JPEN J Parenter Enteral Nutr. 2016;40(2):159-211.

13. Patkova A, Joskova V, Havel E, et al. Energy, protein, carbohydrate, and lipid intakes and their effects on morbidity and mortality in critically ill adult patients: a systematic review. $A d v$ Nutr. 2017;8:624-634.

14. Sands KE, Bates DW, Lanken PN, et al. Epidemiology of sepsis syndrome in 8 academic medical centers. JAMA. 1997;16:234-240.

15. Levy MM, Fink MP, Marshall JC, et al. SCCM/ESICM/ACCP/ATS/ SIS International Sepsis Definitions Conference. Crit Care Med. 2001;2003(16):1250-1256).

16. Vincent JL, Moreno R, Takala J, et al. The SOFA (Sepsis-related Organ Failure Assessment) score to describe organ dysfunction/failure. On behalf of the Working Group on Sepsis-Related Problems of the European Society of Intensive Care Medicine. Intensive Care Med. 1996;22(7):707-710.

17. Mohil RS, Bhatnagar D, Bahadur L, et al. POSSUM and P-POSSUM for risk-adjusted audit of patients undergoing emergency laparotomy. Br J Surg. 2004;91(4):500-503.

18. Parizkova R, Cerny V, Dostal P. The cost in different subgroups of critically ill patients: a multicentric study in Czech Republic. Critical Care. 2001;5(Suppl 1):P259.

19. Weimann A, Singer P. Avoiding underfeeding in severely ill patients. Lancet. 2013;381:1811.

20. Vogel JA, Liao MM, Hopkins E, et al. Prediction of postinjury multiple-organ failure in the emergency department: development of the Denver Emergency Department Trauma Organ Failure score. $J$ Trauma Acute Care Surg. 2014;76(1):140-145.

21. Plauth M, Bernal W, Dasarathy S, et al. ESPEN guideline on clinical nutrition in liver disease. Clin Nutr. 2019;38(2):485-521.

22. Plauth M, Cabré E, Campillo B, et al. ESPEN guidelines on parenteral nutrition: hepatology. Clin Nutr. 2009;28(4):436-444.

23. Salomone F, Li Volti G, Rosso C, et al. Unconjugated bilirubin, a potent endogenous antioxidant, is decreased in patients with non-alcoholic steatohepatitis and advanced fibrosis. $J$ Gastroenterol Hepatol. 2013;28(7):1202-1208.
24. Creeden JF, Gordon DM, Stec DE, et al. Bilirubin as a metabolic hormone: the physiological relevance of low levels. Am J Physiol Endocrinol Metab. 2021;320(2):E191-E207.

25. Gordon DM, Neifer KL, Hamoud AA, et al. Bilirubin remodels murine white adipose tissue by reshaping mitochondrial activity and the coregulator profile of peroxisome proliferator-activated receptor a. J Biol Chem. 2020;295(29):9804-9822.

26. Stec DE, John K, Trabbic CJ, et al. Bilirubin binding to PPAR $\alpha$ inhibits lipid accumulation. PLoS One. 2016;11(4):e0153427.

27. Zhu YD, Guan XQ, Chen J, et al. Neobavaisoflavone induces bilirubin metabolizing enzyme UGT1A1 via PPAR $\alpha$ and PPAR $\gamma$. Front Pharmacol. 2021;11:628314.

28. Shibuya A, Itoh T, Tukey RH, Fujiwara R. Impact of fatty acids on human UDP-glucuronosyltransferase 1A1 activity and its expression in neonatal hyperbilirubinemia. Sci Rep. 2013;3:2903.

29. Abbott SK, Else PL, Atkins TA, et al. Fatty acid composition of membrane bilayers: importance of diet polyunsaturated fat balance. Biochim Biophys Acta. 2012;1818(5):1309-1317.

30. Simons K, Toomre D. Lipid rafts and signal transduction. Nat Rev Mol Cell Biol. 2000;1(1):31-39.

31. Reif S, Tano M, Oliverio R, et al. Total parenteral nutrition-induced steatosis: reversal by parenteral lipid infusions. JPEN J Parenter Enteral Nutr. 1991;15:102-104.

32. Btaiche IF, Khalidi N. Metabolic complications of parenteral nutrition in adults, Part 2. Am J Health Syst Pharm. 2004 Oct 1;61 (19):2050-2057.

33. Manzanares W, Langlois PL, Hardy G. Intravenous lipid emulsions in the critically ill: an update. Curr Opin Crit Care. 2016;22 (4):308-315.

34. Nandivada P, Fell GL, Gura KM, Puder M. Lipid emulsions in the treatment and prevention of parenteral nutrition-associated liver disease in infants and children. Am J Clin Nutr. 2016;103(2):629S-34S.
Therapeutics and Clinical Risk Management

\section{Publish your work in this journal}

Therapeutics and Clinical Risk Management is an international, peerreviewed journal of clinical therapeutics and risk management, focusing on concise rapid reporting of clinical studies in all therapeutic areas, outcomes, safety, and programs for the effective, safe, and sustained use of medicines. This journal is indexed on PubMed Central, CAS,

\section{Dovepress}

EMBase, Scopus and the Elsevier Bibliographic databases. The manuscript management system is completely online and includes a very quick and fair peer-review system, which is all easy to use. Visit http://www.dovepress.com/testimonials.php to read real quotes from published authors. 